\title{
INFLUENNCIA DAS INTRUSÕES ÍGNEAS NOS FOLHELHOS DEVONIANOS DA BACIA DO BAIXO AMAZONAS
}

\author{
DAISY BARBOSA ALVES* e RENÊ RODRIGUES*
}

\begin{abstract}
Illite, mixed-layer illite-smectite and chlorite are the major clay minerals of the Devonian shales of the Lower Amazonas Basin. The absence of chlorite in the radioactive section of the Barreirinha Member (Curuá Formation) is atributed to syndepositional processes (anoxic conditions) that also originated kaolinite and mixed-layer illite-smectite.These rocks are at a high stage of diagenesis and consequently the most evident alterations caused by the intrusion of basic igneous magma are the apperance of pyrophyllite and paragonite derived respectively from kaolinite and mixed-layer illite-smectite. The width of the metamorphic aureole adjacent to the sills at least equals the thickness of the intrusives bodies. At the same time, several alterations occur within the intrusives as they incorpotate fluids from surrounding rocks.
\end{abstract}

INTRODUÇÃo Os folhelhos da Bacia Amazônica têm sido estudados sistematicamente pela Petrobrás com a finalidade de complementar as suas atividades exploratórias na região. Estes estudos incluem informações sobre o conteúdo orgânico e mineralógico dessas rochas, com vistas à detecção dos intervalos geradores de hidrocarbonetos.

Sob o ponto de vista mineralógico, os folhelhos paleozóicos das bacias do Médio e Baixo Amazonas podem ser separados em pelo menos dois intervalos cronolitológicos. Um deles, abrangendo as rochas sedimentares desde a Formação Trombetas (Siluriano) até a discordância pré-pensilvaniana, é caracterizado, principalmente, pela presença de caolinita. O outro, englobando os folhelhos desde a Formação Monte Alegre (Pensilvaniano) até a Formação Andirá (Permiano), praticamente não possui caulinita e o interestratificado clorita-esmectita está presente, essencialmente associado às se- qüências evaporíticas (Alves \& Rodrigues 1984)

Os estudos das variações horizontais dos minerais de argila numa bacia de grandes dimensões, como a Amazônica, é de difícil avaliação em função do amplo espaçamento entre os poços. No entanto, as variações mineralógicas verticais são marcantes e repetitivas, o que possibilita a sua avaliação estatística.

Dentre os folhelhos analisados, os de idade devoniana foram os que apresentaram as variações mineralógicas mais marcantes quando próximos a intrusões de rochas vulcânicas. As amostras analisadas procederam dos poços 2-IB-1APA, 2-BC-1-PA e 2-XU-1-PA (Fig. 1).

MÉTODOS As amostras de calha e de testemunhos de folhelhos foram separadas e analisadas por difração de raios-X para a determinação do conteúdo mineralógico.

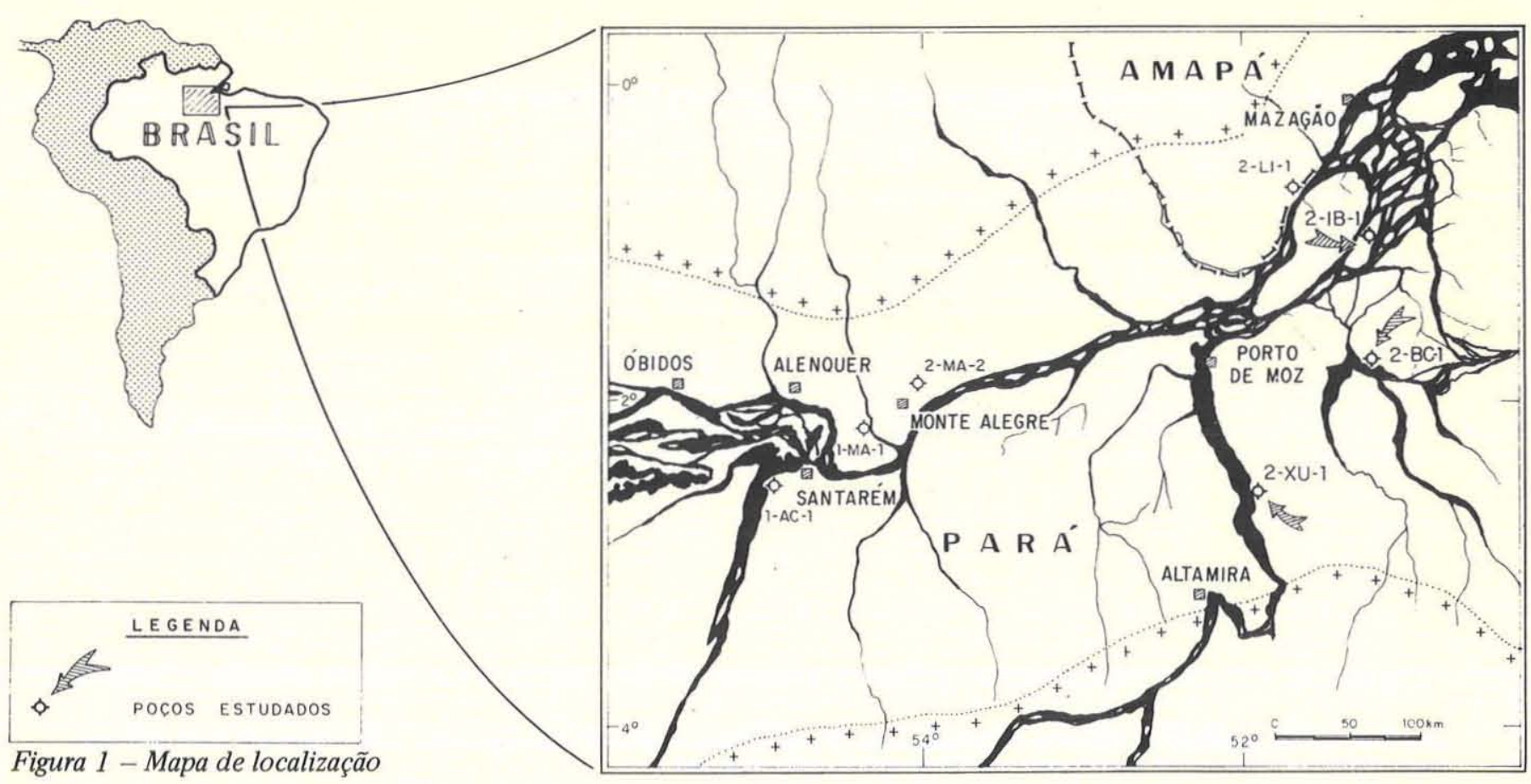

* Petróleo Brasileiro S.A. - Petrobrás Cenpes (Centro de Pesquisas e Desenvolvimento Leopoldo A. Miguez de Mello), CFP 21910, Rio de Janeiro, RJ, Brasil. 
Após a pulverização das amostras, extraiu-se a fração granulomértica inferior a dois micra, onde os minerais de argila se concentram, por separação através de centrifugação segundo a lei de Stokes, modificada por Svedberg (Müller 1967). Este material foi disposto sobre lâminas de vidro, utilizando-se a técnica do smearing para permitir a orientação dos minerais.

As lâminas assim preparadas foram analisadas no difratômetro de raios-X modelo Rotaflex RU 200 da Rigaku, sob as seguintes condições de operação: $100 \mathrm{~mA}, 30 \mathrm{kV}$, fendas convergente e divergente de $0,5^{\circ}$. Em algumas amostras foi usado filtro de níquel, em outras, monocromador de grafita.

As proporções dos minerais de argila, aqui apresentadas em caráter semi-quantitativo, têm a finalidade de detectar tendências e ocorrências mineralógicas diversas.

O conteúdo orgânico dos folhelhos, obtido por combustão no aparelho LECO WR-12, é apresentado em percentagem de carbono orgânico total.

\section{MINERALOGIA DE ARGILAS DOS FOLHELHOS DEVO-} NIANOS O Devoniano da Bacia Amazônica compreende as formações Maecuru, Ererê e Curuá, depositadas em ambiente predominantemente marinho (Rodrigues et al. 1971, Caputo et al.1972). Os minerais de argila encontrados nos folhelhos destas formações foram: ilita, interestratificado ilita-esmectita, caulinita e clorita. A seção estratigráfica que compreende os poços 2-IB-1A-PA, 2-BC-1-PA e 2-XU-1 -PA mostra a distribuição destes minerais (Fig. 2).

A clorita se faz presente em quantidades significativas em praticamente todos os folhelhos paleozóicos da Bacia do Baixo Amazonas, exceto na seção basal do Membro Barreirinha. Essa seção, onde são observados os teores mais elevados de carbono orgânico, é marcada por um aumento acentuado de radioatividade, bem visível nos perfis de raios gama (Fig. 2), e se constitui na melhor seqüência geradora de petróleo da bacia (Rodrigues \& Santos 1982, Rodrigues 1982).

A ausência de clorita neste intervalo só poderia ser resultante de processos pré- ou sin-deposicionais, uma vez que as reações diagenéticas normais favorecem a formação e preservação deste mineral.

Sabe-se que a preservação da matéria orgânica somente é possível em condições anóxicas, mantidas pela atividade de bactérias aneróbias. Estas bactérias utilizam o pouco oxigênio livre e aquele dos nitratos e sulfatos da água do mar na decomposição de parte da matéria orgânica depositada e liberam $\mathrm{CO}_{2}, \mathrm{~N}_{2}$ e $\mathrm{H}_{2} \mathrm{~S}$. $\mathrm{O}$ meio altamente redutor assim originado, associado a condições de $\mathrm{pH}$ ácidos, é adverso a preservação das cloritas, principalmente as ferríferras, pois promove a mobilização do ferro nelas contido para a formação de pirita. Por conseguinte, outros minerais estáveis a estas condições são formados (Love 1967, Drever 1971, Siever \& Kastner 1972, Gossman et al. 1979).

A anoxidade em que foi depositada a seção basal do Membro Barreirinha provocou a transformação da clorita em caulinita e interestratificados ilita-esmectita. Conseqüentemente, a ausência de clorita é resultante de um processo sin-deposicional. A caulinita assim formada, por sua vez, não tem qualquer conotação paleoclimática, como também

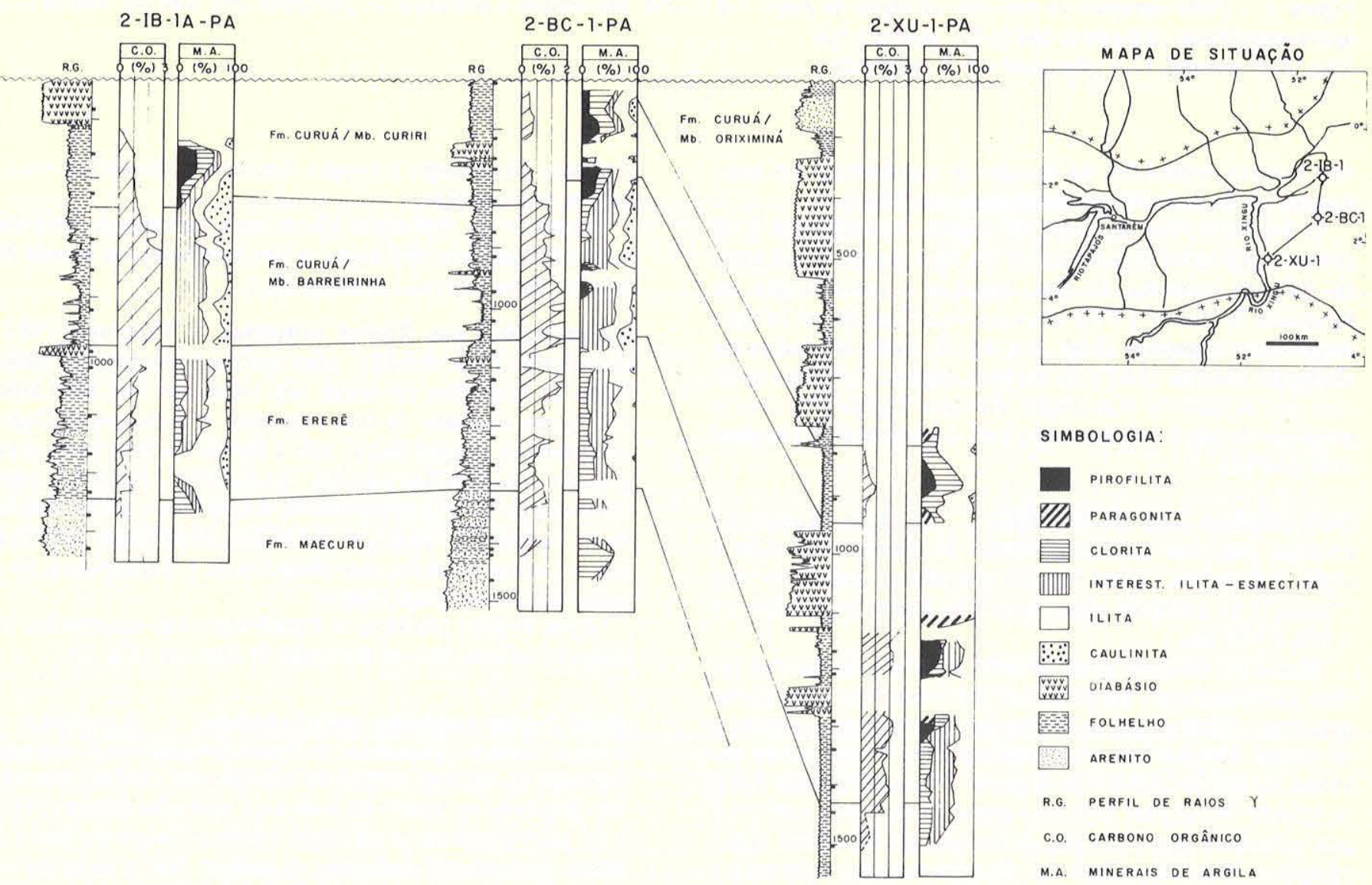

Figura 2 - Variações mineralógicas associadas às intrusões de diabásio na Bacia do Baixo Amazonas 

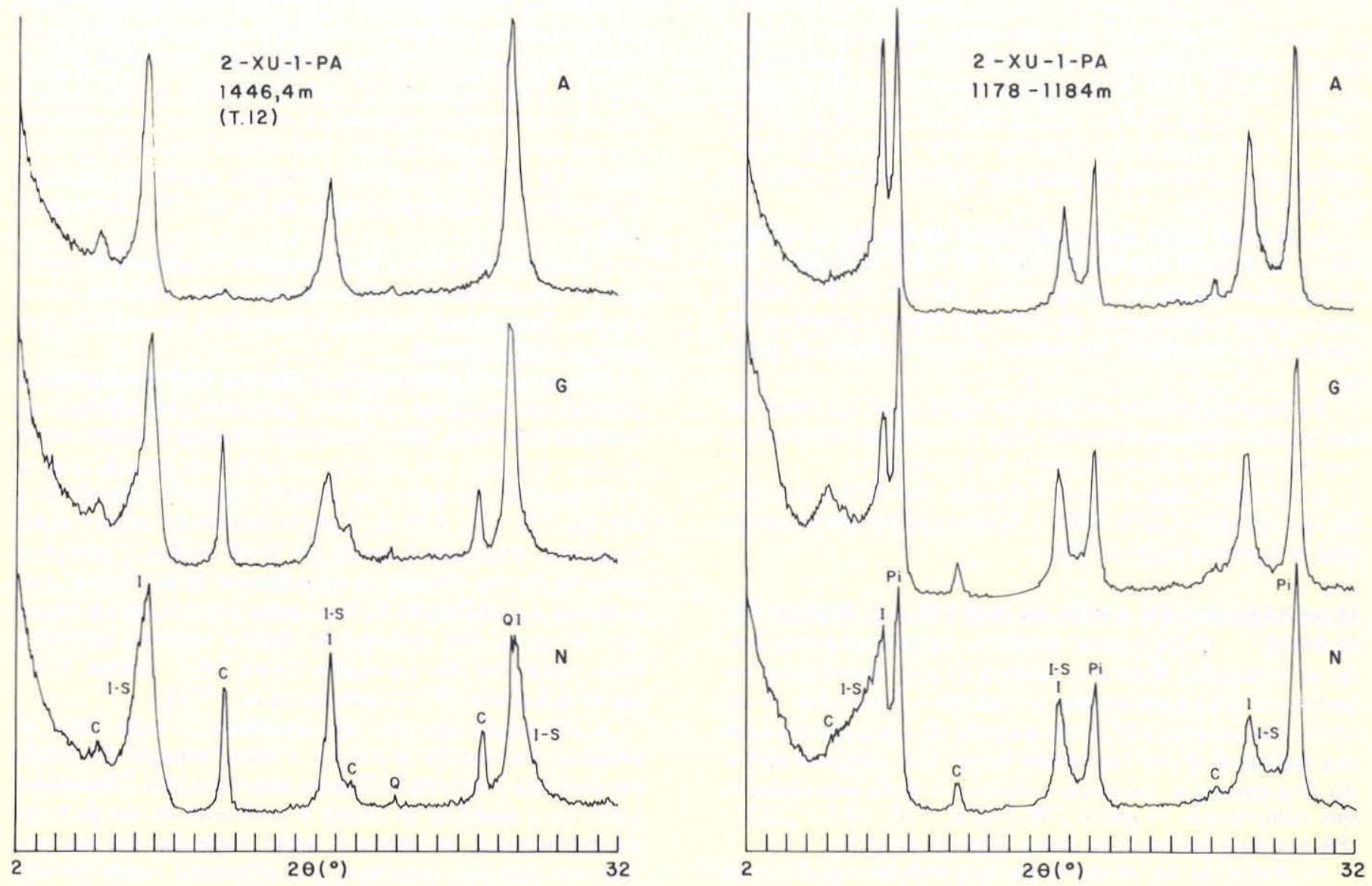

Figura 3 - Difratogramas de minerais de argila do poço 2-XU-1PA, mostrando a presença de: pirofilita (Pi), ilita (I), clorita $(C)$, interestratificado ilita-esmectita $\left(I_{-}-S_{-}\right.$, quartzo $(Q)$.

Obs.: $N=$ normal, $G=$ glicolada e $A=$ aquecida

não fornece indicações da direção de suprimento dos sedimentos ou de variações mineralógicas nas fontes.

$\mathrm{O}$ conjunto dos minerais de argilas identificados e os interestratificados ilita-esmectita do tipo regular (com mais de $65 \%$ de camadas de ilita, segundo a metodologia de Reynolds \& Hower 1970) são característicos de um estágio diagenético avançado (Figs. 3 e 4). Os dados de índice de alteração térmica (IAT) da matéria orgânica também indicam um estágio de maturação elevado, compatível com a presença de gás e condensado (Tab. 1), segundo Rodrigues et al. (1984).

INFLUÊNCIA DAS INTRUSÕES Na Bacia Amazônica existem inúmeras soleiras e diques de diabásio em toda a seção paleozóica. Aires (1983) identificou doze períodos ("picos") de atividade ígnea básica de idades que variam de 1.900 a $150 \mathrm{Ma}$.

Mudanças mineralógicas diversas são introduzidas nas rochas próximas aos corpos ígneos intrusivos, em resposta ao gradiente térmico que se forma entre o magma aquecido e as rochas hospedeiras relativamente frias, constituindo auréolas de metamorfismo de contato. No entanto, nem todas as rochas localizadas próximo aos contatos com estes corpos intrusivos apresentaram as mesmas modificações mineralógicas. Elas dependem de diversos fatores: espessura e temperatura da intrusiva, profundidade em que se deu a intrusão, mineralogia e estágio diagenético das rochas encaixantes, entre outros.

Somente os folhelhos devonianos mostraram auréolas metamórficas bem definidas, o que justificou um estudo de detalhe deste intervalo estratigráfico.

Características das Rochas Intrusivas Pimentel (1983) classificou como diabásio com textura holocristalina subofítica as intrusões de idade em torno de $165 \mathrm{Ma}$ (Aires 1983) que ocorrem na área estudada. A suíte mineralógica compreende: plagioclásios, sob a forma de ripas com composição andesina/labradorita; piroxênios, maclados com composição de augita/pigeonita; magnetita; e pirita. São visíveis índicios de alteração deutérica: cloritização, uralitização e carbonatização dos piroxênios; e carbonatização e sericitização dos plagioclásios.

Aires (1983) mostrou a distribuição das ocorrências de diabásio na área através do mapa de isópacas (Fig. 5).

Modificações induzidas pelas Intrusões A presença de corpos ígneos promoveu o desenvolvimento de espessas auréolas de metamorfismo de contato nas rochas encaixantes. Segundo os dados do índice de alteração térmica (IAT) e do paleogradiente geotérmico estabelecido para a Bacia do Médio Amazonas (Rodrigues \& Santos 1982), as rochas sedimentares analisadas estão em estágio diagenético avança- 

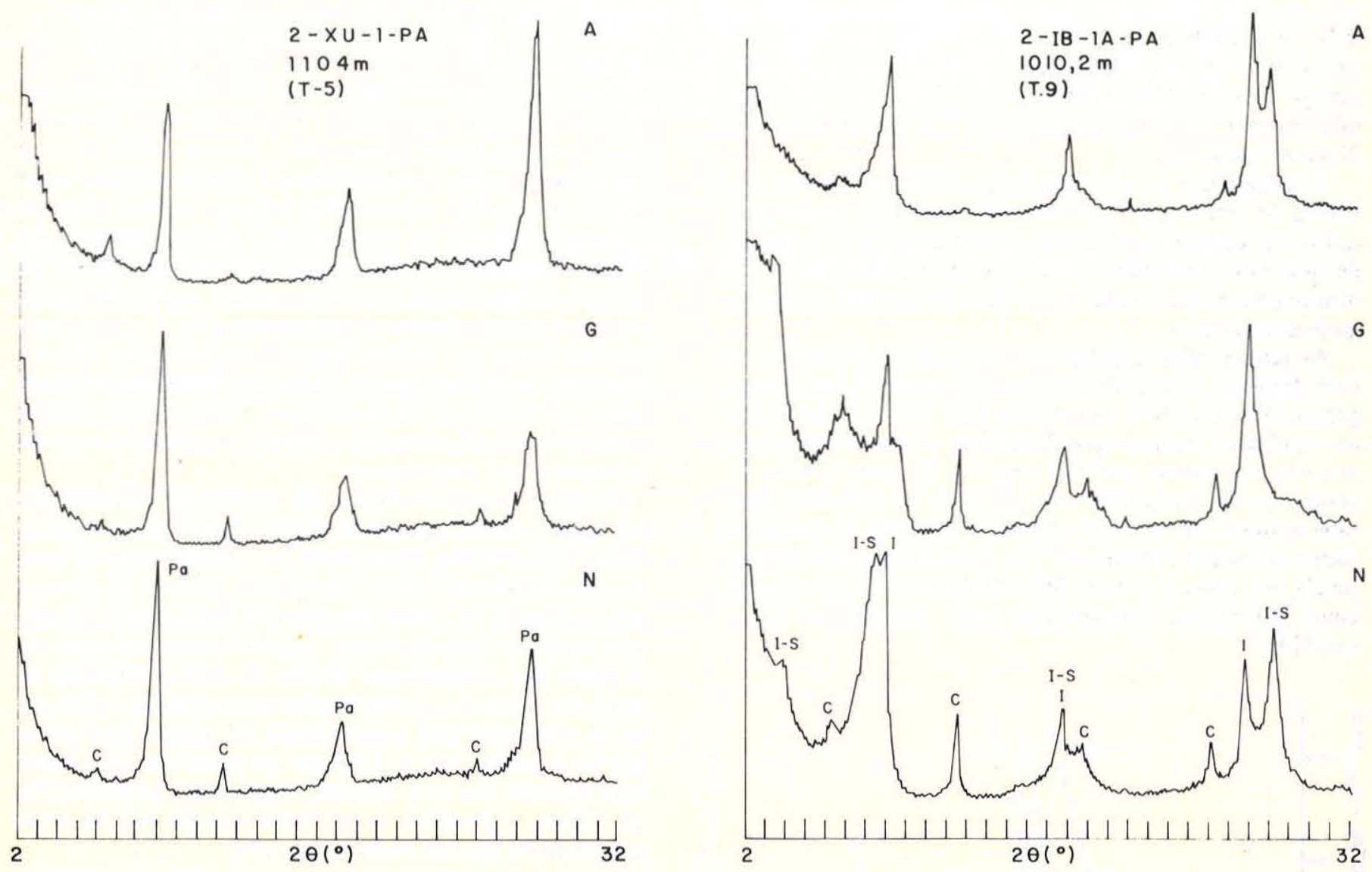

Figura 4 - Difratogramas de minerais de argila dos poços 2-XU-1-PA e 2-IB-1A-PA, mostrando a presença de: paragonita (Pa), clorita (C), ilita (I) e interestratificado ilita-esmectita (I-S).

Obs. : $N=$ normal,$G=$ glicolada $e A=$ aquecida

\begin{tabular}{c|c|c|c}
\hline Poço & $\begin{array}{c}\text { Intervalo } \\
(\mathrm{m})\end{array}$ & $\begin{array}{c}\text { Amostra } \\
\text { Calha }=\text { A.C. } \\
\text { Test. }=\text { T. }\end{array}$ & $\begin{array}{c}\text { Indice de alte- } \\
\text { ração térmica } \\
\text { (IAT) }\end{array}$ \\
\hline 2-BC-1-PA & $844-850$ & A.C. & $3,75 / 4,00$ \\
& $871-874$ & A.C. & $3,75 / 4,00$ \\
& $895-901$ & A.C. & $3,75 / 4,00$ \\
& $911-912$ & T-7 & $3,75 / 4,00$ \\
& $979-985$ & A.C. & $3,75 / 4,00$ \\
& $1021-1024$ & T-9 & 4,00 \\
& $1048-1054$ & A.C. & 4,00 \\
2-IB-1-PA & $800-802$ & T-5 & $3,25 / 3,50$ \\
& $852-854$ & T-6 & 3,50 \\
& $920-922$ & T-7 & 3,50 \\
& $948-954$ & A.C. & $3,50 / 3,75$ \\
& $966-972$ & A.C. & $3,75 / 4,00$ \\
& $1008-1014$ & A.C. & $3,75 / 4,00$ \\
2-XU-1-PA & $1164-1167$ & T-6 & $3,75 / 4,00$ \\
& $1207-1210$ & T-7 & $3,75 / 4,00$ \\
& $1289-1292$ & T-8 & $3,75 / 4,00$ \\
& $1338-1341$ & T-9 & $3,75 / 4,00$ \\
& $1401-1405$ & T-11 & $3,75 / 4,00$ \\
\hline
\end{tabular}

Tabela 1 - Dados do indice de alteração térmica (IAT) do Membro Barreiirinha da Formação Curuá (Rodrigues et al. 1984)

do, evidenciando que já estiveram a profundidades superiores a 3.500 metros. A estas profundidades podem-se associar pressões de 1 a $2 \mathrm{~kb}$, que permitiram a aceleração das reações diagenéticas e facilitariam o desenvolvimento de meta-

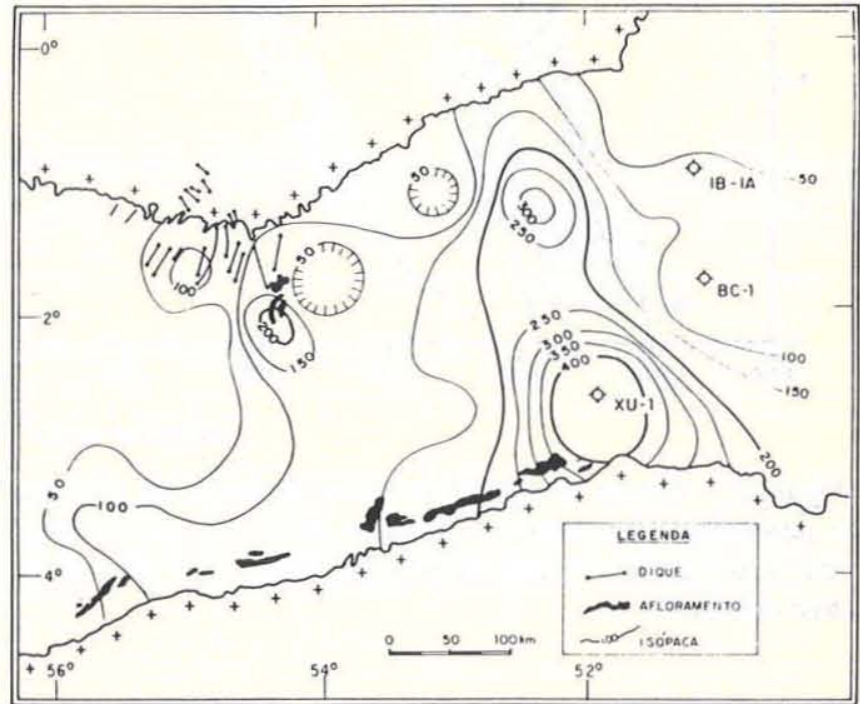

Figura 5 - Mapa de isópacas dos diabásios presentes nos sedimentos do Devoniano e Carbonifero Inferior da Bacia do Baixo Amazonas (Aires 1983)

morfismo de contato nas rochas próximas às intrusões.

$\mathrm{O}$ desenvolvimento de auréolas metamórficas dentro dos folhelhos do Devoniano da Bacia do Baixo Amazonas somente ocorre próximo aos corpos intrusivos mais espessos 
(Fig. 2) e depende da composição mineralógica inicial da rocha encaixante (poço 2-IB-1A-PA, Fig 4). Assim, auréolas melhor desenvolvidas aparecem nas rochas cuja composição mineralógica inicial incluía caulinita, ilita, interestratificado ilita-esmectita e clorita.

À medida que se aproxima das intrusões, observa-se: tendência de diminuição dos teores de caulinita e interestratificados ilita-esmectita; aumento de ilita e clorita; e formação de dois novos minerais: pirofilita e paragonita (Fig. 2). Os difratogramas das Figuras 3 e 4 ilustram as suítes mineralógicas identificadas.

As reações mineralógicas que originam a pirofilita estão bem definidas na literatura, o que não acontece com a paragonita, um mineral de ocorrência mais rara. Exitem curvas de equilíbrio térmico que delimitam a ocorrência desses min rrais em rochas pelíticas (Fig. 6). O limite inferior de ocorrência de paragonita não foi ainda determinado, mas sabe-se que a sua aparição se faz em condições de metamorfismo incipiente (Winkler 1977). O limite superior de ocorrência, no entanto, é bem definido e posiciona a paragonita como estável em temperaturas mais elevadas do que a pirofilita.

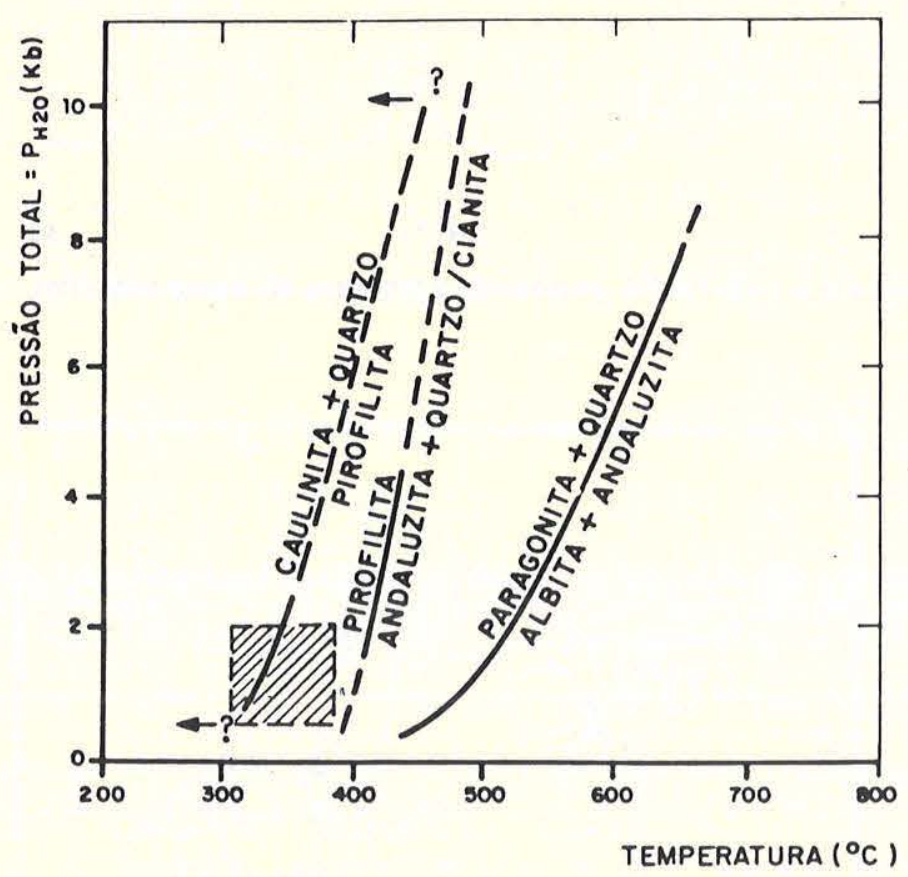

Figura 6 - Curvas de equilibrio termodinâmico de pirofilita e paragortita (baseado em Winkler 1977). A parte hachurada representa as condições de estabilidade dos minerais na área estudada.

A pirofilita se forma a partir da reação de caulinita + quartzo. Esse fato é bem vísivel no poço 2-IB-1A-PA (entre 600 e 700metros) pela diminuição gradativa de caulinita e aparecimento concomitante da pirofilita. Associada a ela, também se forma a clorita (Fig. 2)

Várias reações foram propostas para a formação da paragonita. Zen (1960 in Miyashiro 1975) sugere que a associação albita + caulinita originaria paragonita + quartzo. Frey (1969 in Winkler 1977) sugere que o interestratificado ilita-esmectita forma paragonita + ilita + clorita. Winkler (1977) admite que a albita, em contato com pirofilita, reage para formar paragonita.

Os fluidos contidos nos poros da rocha encaixante desempenham papel fundamental no desenvolvimento dessas reações mineralógicas (Turner 1968, Winkler 1977). O calor emanado do corpo intrusivo é usado, inicialmente, na vaporização da água dos poros ou para iniciar reações metamórficas endotérmicas de desidratação e descarbonização nas rochas encaixantes, o que é visualizado pela diminuição do teor de carbono orgânico e dos minerais expansivos próximo aos corpos intrusivos mais espessos (Fig. 2). $\mathrm{O}$ decréscimo dos teores de carbono orgânico, por sua vez, altera a coloração das rochas, que se tornam progressivamente mais claras em direção ao corpo intrusivo. Este processo diminui a temperatura nos contatos e limita a largura das auréolas internas de alta temperatura.

Magmas intrusivos básicos são geralmente subsaturados em água e podem incorporar fluidos (água e gás carbônico) oriundos das rochas encaixantes nas proximidades da zona de contato (Turner 1968). Tais fluidos, por sua vez, promovem alterações na rocha intrusiva em cristalização, conforme observado através de suas características petrográficas. A perda dos componentes fluidos da rocha encaixante retarda em muito as transformações mineralógicas, como pode ser observado pela sobrevivência da caulinita bem próximo ao contato com a intrusiva, ao passo que um pouco mais afastado seu teor diminui, originando a pirofilita (Fig. 2). Assim, a pirofilita só se forma quando não há perda acentuada de água na rocha encaixante.

A paragonita parece ser mais estável quanto a este aspecto, pois forma-se no mesmo intervalo em que as perdas acontecem, aparentemente às custas do interestratificado ilita-esmectita. A presença daquele mineral parece estar associada a pressões parciais de água menores do que aquelas necessárias à formação de pirofilita, as quais foram ocasionadas pela mobilização do fluido para o corpo intrusivo. Assim, a reação para a formação deste mineral poderia ser: ilita-esmectita + albita $=$ paragonita + ilita.

De acordo com os dados apresentados, pode-se formular, um resumo esquemático das transformações observadas na mineralogia das argilas (Fig. 7), tanto as oriundas de processos sin-deposicionais, como as devidas à influência das intrusões ígneas (metamorfismo de contato).

$\mathrm{O}$ desenvolvimento de auréolas mais espessas e com mineralogia mais diversificada é observado no poço 2-XU-1-PA (fig. 2), que se situa na área com as maiores espessuras de corpos intrusivos (Fig. 5). Nesta área as temperaturas foram mais altas e permitiram diversas reações que provocaram o desaparecimento acentuado dos interestratificados ilita-esmectita, com a formação subseqüente da paragonita.

Como pode ser visto na Figura 2, a espessura das rochas sedimentares que sofreram modificações mineralógicas pela influência das intrusões corresponde, pelo menos, a um intervalo equivalente a uma vez a espessura da intrusiva. No entanto, quando ocorre maior densidade de intrusões, como no caso do poço 2-XU-1-PA, esses efeitos se superpõem e tornam-se de difícil avaliação.

CONCLUSÕES Os folhelhos devonianos da Bacia do Baixo Amazonas são constituídos basicamente por ilita caulinita, interestratificado ilita-esmectita regular e clorita. $\mathrm{O}$ desaparecimento de clorita na seção radioativa basal do 


\section{MINERAIS DETRITICOS}

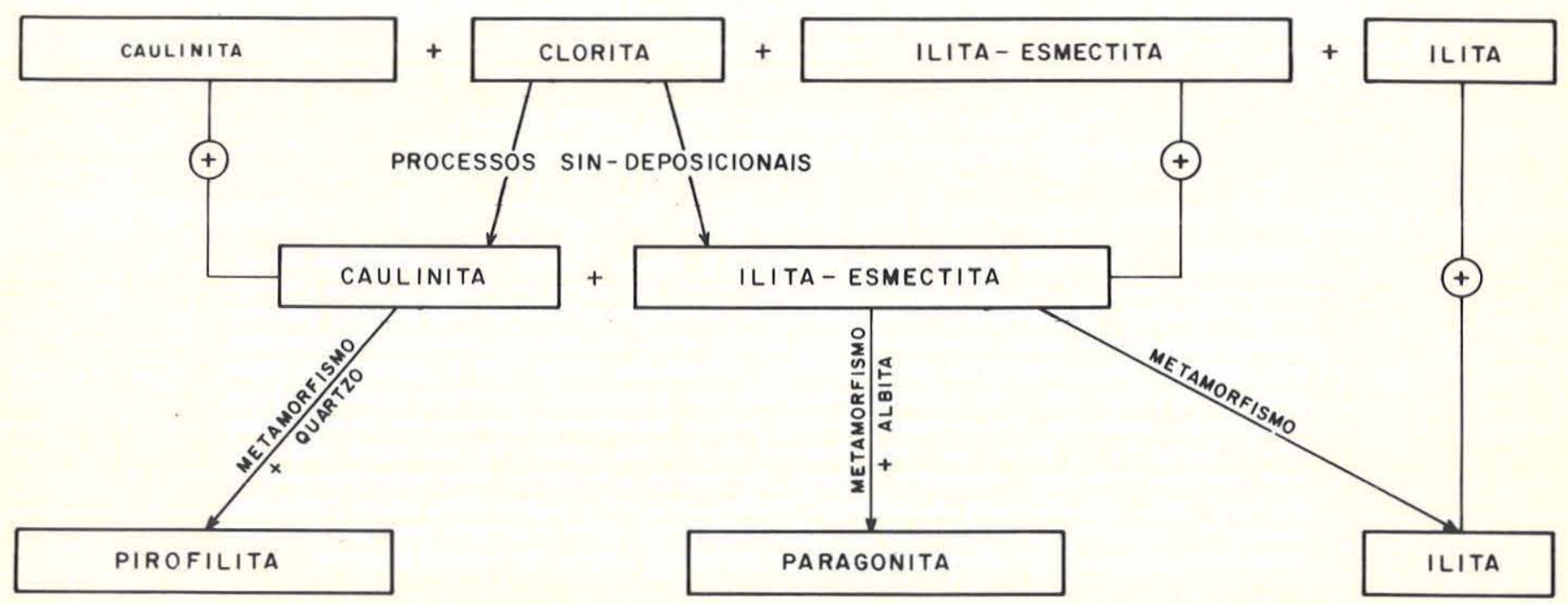

Figura 7 - Mineralogia de argilas dos folhelhos do Devoniano da Bacia do Baixo Amazonas e suas principais transformaçčes

Membro do Barreirinha é resultante da ação de processos sin-sedimentares (sob condições anóxicas), também responsá veis pelo aumento do teor de caulinita e de interestratificado ilita-esmectita. Este aumento de teor de caulinita não está, conseqüentemente, relacionado com variações climáticas ou com o suprimento de sedimentos.

As modificações mineralógicas induzidas pelos efeitos das intrusões estão diretamente relacionadas com: a composição mineralógica e o estágio diagenético das rochas encaixantes; a espessura da intrusiva; e a profundidade em que ocorreu a intrusão.

A evolução diagenética dos minerais de argila e da matéria orgânica posiciona os folhelhos devonianos da área estudada em estágio avançado de diagênese (zona de gás e con- densado). Assim sendo, as transformações mineralógicas mais notáveis foram aquelas produzidas pelo efeito de metamorfismo de contato, com aparecimento de pirofilita e paragonita.

A pirofilita se formou a partir da reação caulinita + quartzo. A paragonita, presente em condições de metamorfismo um pouco mais elevado, parece ter-se originado pela re'ação ilita-esmectita + albita = paragonita + ilita .

A espessura dos folhelhos que sofreram modificações mineralógicas incluzidas pelas intrusões corresponde pelo menos uma vez à espessura do corpo intrusivo.

Os corpos intrusivos assimilam fluidos provenientes da rocha encaixante (água, gás carbônico), e alterações diversas são observadas nos seus componentes mineralógicos.

\section{REFERÊNCIAS BIBLIOGRÁFICAS}

AIRES, J.R. - 1983 - Estudo do vulcanismo básico da Bacia do Amazonas. Rio de Janeiro, Petrobrás/Cenpes (relatório inédito).

ALVES, D.B. \& RODRIGUES, R. - 1984 - Estudo das argilas da sequêencia paleozóica da Bacia do Médio Amazonas. Rio de Janeiro, Petrobrás/Cenpes (relatório inédito).

CAPUTO, M.V.; RODRIGUES, R.; VASCONCELOS, D.N.N. - 1972 - Nomenclatura estratigráfica da Bacia do Amazonas: histórico e atualização. In: CONGR. BRAS. GEOL., 26, Belém, 1972. Anais... Belém SrG, v. 3, p. 35-46.

DREVER, J.I. - 1971 - Magnesium-iron replacement in clay minerals in anoxic marine sediments. Science, 172: 1334-1336.

GROSSMAN, R.H.; LIEBLING, R.S.; SCHERP, H.S. - 1979 Chlorite and its relationship to pyritization in anoxic marine environments. J. Sed. Petrol., 49: (2): 611-614.

LOVE, L.G. - 1967 - Early diagenetic iron sulphide in recent sediments of the Wash (England). Sedimentology, 9: 327-352.

MIYASHIRO, A. - 1975 - Metamorphism and metamorphic belts. London. George Allen \& Unwin Ltd., 1 ed. 492 p.

MÜLLER, G. - 1967 - Methods in sedimentary petrology. Stuttgart. E. Schweizerbart'Sche, $283 \mathrm{p}$.

PIMENTEL, A.M.B. - 1983 - Análises petrográficas. Rio de Janeiro, Petrobrás/Cenpes (comumunicação técnica inédita.).

REYNOLDS, Jr., R.C. \& HOWER, J. - 1970 - The nature of interlayering in mixed-layer illite-montmorillonites. Clays and clay minerals, 18: 25-36.
RODRIGUES, E.; VASCONCELOS, D.N., CAPUTO, M.V. - 1971 Sedimentologia das formações pré-pensilvanianas da Baica do Amazonas. Rio de Janeiro, Petrobrás/Dexpro (relatório inédito).

RODRIGUES, R. \& SANTOS, A. - 1982 - Avaliação geoquimica da Bacia do Médio Amazonas. Rio de Janeiro, Petrobrás/Cenpes (relatório inédito).

RODRIGUES, R. - 1982 - Avaliação geoqutmica da Bacia Amazônica. Rio de Janeiro, Petrobrás/Cenpes (relatório inédito).

RODRIGUES, R.; TAKAKI, T.: CAPUTO, M. V.; CARNEIRO, R. G. e MARQUES, L. F. S. - 1984 - Avaliação geoquímica da Bacia do Baixo Amazonas: 1983. Rio de Janeiro, Petrobrás/Cenpes (relatório inédito).

SIEVER, E. \& KASTNER, M. - 1972 - Shale petrology by electron microprobe: pyrite-chlorite relations, J. Sed. Petrol., 42 (2): 350-355.

TURNER, F. J. - 1968 - Metamorphic petrology: mineralogical and field aspects. 1. ed., New Yörk, MacGraw-Hill, 403 p.

WINKLER, H. G. F. - 1977 - Petrogēnese das rochas metamórficas. São Paulo, Edgard Blücher, 257 p.

MANUSCRITO

Recebido em 01 de fevereiro de 1985 Revisão aceita em 18 de junho de 1985 